\title{
A Large-Scale Systematic Study of Dorset and Groswater Soapstone Vessel Fragments from Newfoundland and Labrador
}

\author{
John C. Erwin ${ }^{1}$
}

(Received 19 February 2016; accepted in revised form 21 April 2016)

\begin{abstract}
The examination of Paleo-Inuit soapstone vessel fragments from the Province of Newfoundland and Labrador provides a better understanding of the use and significance of this technology. While researchers have tacitly accepted the function of soapstone vessels and their use by these populations on the basis of ethnographic analogy, no large-scale systematic study of these vessels has ever been produced to test these assumptions in this region. Results of this study, which are based upon the measurement of more than 3600 soapstone vessel fragments, demonstrate ways in which vessel function may be determined from both morphological characteristics and carbonization patterns. It is also concluded that there are recognizable stylistic differences between vessels used in Labrador and those used on the Island of Newfoundland. The methods employed in this study may be useful in the examination of similar vessels elsewhere in the Arctic.
\end{abstract}

Key words: soapstone; Paleo-Inuit; Dorset; Groswater; regional variation

RÉSUMÉ. L'examen de fragments de récipients en stéatite du Paléo-Inuit en provenance de la province de Terre-Neuve-etLabrador permet de mieux comprendre l'utilisation de cette technologie et son importance. Bien que les chercheurs aient tacitement accepté la fonction des récipients en stéatite et leur utilisation par ces populations en s'appuyant sur une analogie ethnographique, aucune étude systématique d'envergure n'a jamais été réalisée à l'égard de ces récipients pour valider ces hypothèses dans cette région. Les résultats de cette étude, comportant la mesure de plus de 3600 fragments de récipients en stéatite, montrent comment la fonction des récipients peut être déterminée tant à partir des caractéristiques morphologiques que des marques de carbonisation. L'étude permet également de conclure qu'il existe des différences stylistiques reconnaissables entre les récipients employés au Labrador et ceux utilisés sur l'île de Terre-Neuve. Les méthodes employées dans le cadre de cette étude pourraient aider à examiner des récipients semblables, ailleurs dans l'Arctique.

Mots clés : stéatite; Paléo-Inuit; Dorset; Groswater; variante régionale

Traduit pour la revue Arctic par Nicole Giguère.

\section{BACKGROUND}

A number of Arctic-adapted groups, including the Inuit, have a long history of soapstone use throughout the Arctic. This study is limited, however, to the pre-Inuit cultures of the province of Newfoundland and Labrador, which can be classified into Early and Late periods (Tuck and Fitzhugh, 1986). The cultures within the Early Period, dating from about 4500 to 1900 BP, generally include Pre-Dorset and Groswater. The Late Period refers to Dorset culture, which is archaeologically discernible from about 2500 to 600 years BP and is marked by three cultural phases described as Early, Middle, and Late Dorset. On the Island of Newfoundland, Dorset culture is limited to the Middle Dorset, which existed between 2000 and 1200 years BP (Tuck and Fitzhugh, 1986:165).

The prehistoric use of soapstone vessels in the province of Newfoundland and Labrador is attributed to both the Dorset (from about 2000 to $1200 \mathrm{BP}$ ) and Groswater (from about 2800 to $1900 \mathrm{BP}$ ). The known prehistory of these groups on the Island of Newfoundland is understood from a small number of intensively studied sites (Fig. 1), the most important of which is Phillip's Garden (EeBi-1) at Port au Choix, which is also the largest known Dorset habitation site in the province (See Renouf, 2011). Other influential sites include Phillip's Garden East (EeBi-1) and Phillip's Garden West (EeBi-11) in Port au Choix; Cape Ray (CdBt-1) on the southwestern coast in Port aux Basques; the Pittman Site (DkBe-1) on the northeastern coast; and Stock Cove (CkAl-3) on the southeastern coast. In Labrador, in contrast to the Island of Newfoundland, an understanding of Dorset and Groswater cultures is largely derived from numerous sites. Some of the most influential research projects in Labrador that have led us to our present understanding of Dorset include Cox's (1977) work in the Okak region, Tuck's (1975) research in Saglek Bay, Thomson's (1985) excavations on Shuldham Island, and the extensive work of Fitzhugh (1972, 1976a, b, 1980) along the northern coast.

\footnotetext{
${ }^{1}$ Department of Business, Tourism, Culture and Rural Development, Government of Newfoundland and Labrador, PO Box 8700 ,

St. John's, Newfoundland and Labrador A1B 4J6, Canada; johncerwin@gmail.com

(C) The Arctic Institute of North America
} 


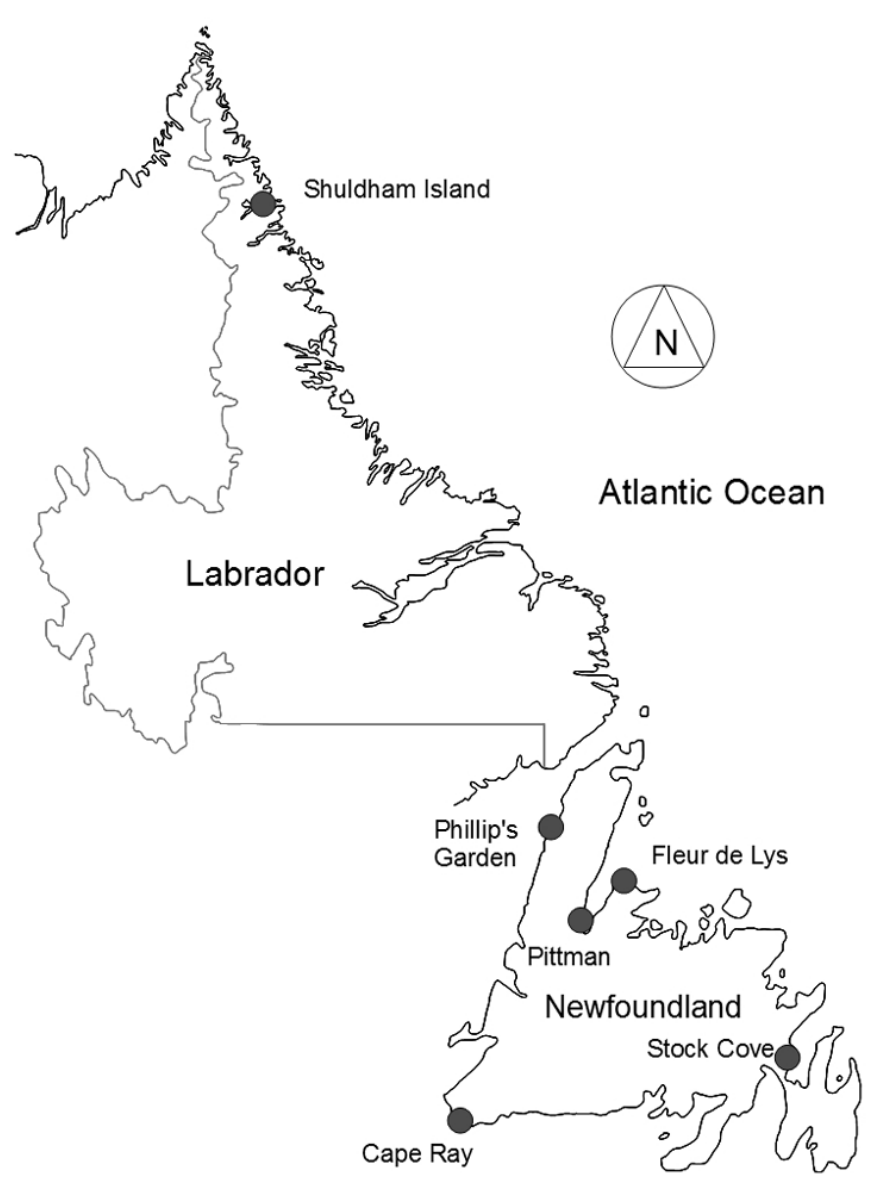

FIG. 1. Map showing areas in Newfoundland and Labrador where soapstone vessels discussed in this paper were found.

Soapstone sources are few throughout Newfoundland and Labrador, and except for the spectacular site at Fleur de Lys (Fig. 1), they show little evidence of quarrying activities (Nagle, 1984:113-116). The only known source of soapstone on the Island of Newfoundland with evidence of working was first documented by T.G.B. Lloyd, who suggested that the soapstone deposits on the northeastern coast of the Island were likely the source of the soapstone artifacts that he had collected from Sop's Island. Lloyd concluded that "the larger stone vessels were probably used for boiling seals' fat, and the smaller ones, as suggested to me, may have been designed for lamps, as amongst the Eskimos" (Lloyd, 1876:237). Despite a century of subsequent archaeological investigations, no systematic analysis of the soapstone quarry at Fleur de Lys was done until the early 1980s (see Nagle, 1982; Thomson, 1985, 1989), nor had there been a systematic province-wide study of finished vessels until now.

This study is intended as a counterpart to the research conducted at the Fleur de Lys soapstone quarry (see Fig. 1), where the significance of this largest and best-preserved known Dorset culture soapstone quarry was investigated (see Erwin, 1998, 1999, 2001, 2003, 2005). The quarry investigations, which were conducted in the town of Fleur de Lys on the northeastern coast of the Island of
Newfoundland, demonstrated the extent and complexity of the quarry deposits, defined the Dorset quarrying and vessel fabrication tool kit, and suggested that the quarry was used primarily by local Dorset groups who occupied the White Bay region of northeastern Newfoundland. However, only half of the evidence had been examined, that is, only the means of vessel production, and not the finished vessels themselves. A more complete understanding of the Dorset use of soapstone would also require the study of finished vessels and their use. This work is important insofar as there had yet to be any large-scale systematic study of Paleo-Inuit soapstone vessels in Newfoundland and Labrador, despite a wealth of archaeological evidence that can be employed to explore regional differences and vessel functions and to test the hypotheses raised by the original quarry research.

\section{METHODS AND HYPOTHESES}

In setting the initial course for this investigation in 2002 , it was necessary to determine what soapstone collections would be used. To this end, the sampling strategy included the examination of every available specimen from the province's two main repositories of soapstone specimens: (1) about 2000 specimens from The Rooms Provincial Museum and (2) about 1700 pieces from the Port au Choix collections at Memorial University. Other than the few pieces that were on loan, or on display at various museums, or held at the former Canadian Museum of Civilization, this assembly of soapstone represented the vast majority of all Paleo-Inuit soapstone that had been recovered. It was therefore possible to make reliable observations, with strong confidence, about the following subjects: 1) the geographic distribution of soapstone vessels between and within the Island of Newfoundland and Labrador, 2) the metric and stylistic attributes of vessels, 3) residue and burning patterns, and 4) potential regional differences in vessel form and function.

As for newly collected specimens, a survey of the unpublished and published literature from 2003 to 2014 indicated that there had been fewer than a dozen reports of soapstone recovered from Dorset and Groswater sites, with the only substantial collection being made from the Chest Head Site (EfAx-02) on the northeastern side of the Great Northern Peninsula. Though these collections are not included in this study, their subsequent review could be used to further test the hypotheses put forward here.

Several hypotheses regarding the metric attributes of soapstone vessels were originally devised for this research. These included 1) that differences in vessel size and shape are a result of function, and that function might be revealed by burn and residue patterning on utilized vessels; 2) that vessels more than $30 \mathrm{~cm}$ in length or width were not fashioned at the Fleur de Lys quarry, as the preform scars were no larger than this; 3) that regional variation in Dorset culture may be reflected in finished vessel styles, which were 
not apparent in the preform scars at the quarry; and 4) that the two small vessel forms identified at the quarry might be explained as the difference between the production of hand lamps and children's "little pots."

The fourth hypothesis, which has been dealt with elsewhere (see Erwin, 2010), concluded that the task of quarrying was not necessarily a specialized task, but a socially complex activity that involved play and learning, which is comparable to Thule Inuit practices. This paper is therefore limited to the first three hypotheses, and the findings presented are related to 1) geographic distribution, 2) vessel metrics, and 3) residue patterning.

\section{GEOGRAPHIC DISTRIBUTION}

In view of the regionally distinct Dorset groups that have been suggested by Robbins (1985, 1986), LeBlanc (2008) and others, it was expected that some patterning with regard to vessel size and shape might be observable in the distribution of soapstone vessels throughout the province. These findings, of course, need to be considered with some caution, owing to the fact that the amount of soapstone recovered in any area is proportional to a number of contextual and research factors. Such factors include deposition and post-depositional processes that influence fragmentation of the vessels (and thus counts), as well as the types of archaeological investigation (e.g., surface collection, shovel testing, full excavation), which will result in differing amounts of soapstone recovered. With these research limitations in view, the results are summarized in Figures 2 and 3 and described below.

In total, 3644 specimens from 57 sites across the province were examined. Geographically these were distributed as follows: 1) On the Island of Newfoundland: 2647 specimens from 29 sites, with Phillip's Garden (EeBi-1) accounting for $64 \%$ (1695) of the soapstone vessels and $47 \%$ of all soapstone vessels in the entire province; and 2) In Labrador: 997 specimens from 26 sites, with Shuldham Island 9 (IdCq-22) accounting for 69\% (688) of the soapstone vessels and $19 \%$ of all soapstone vessels in the province. Combined, Phillip's Garden and Shuldham Island account for $65 \%$ (2383) of the 3644 soapstone vessels in the province.

The presence or absence of soapstone vessels on Dorset sites has long been cited as an indicator of seasonality, with the presence of soapstone being equated to cold weather occupations and associated with more permanent-type structures. While the geographic distribution does not contradict these observations, it is notable that both the Phillip's Garden and Shuldham Island sites are not only cold weather, early spring seal hunting occupations, but that Phillip's Garden is also considered an aggregation spot with social significance, while Shuldham Island 9 is better known for its high concentration of Dorset soapstone carvings of animals that have been identified with shamanistic pursuits and miniature vessels. Likewise, it is also important to note that the large size of Phillip's Garden,

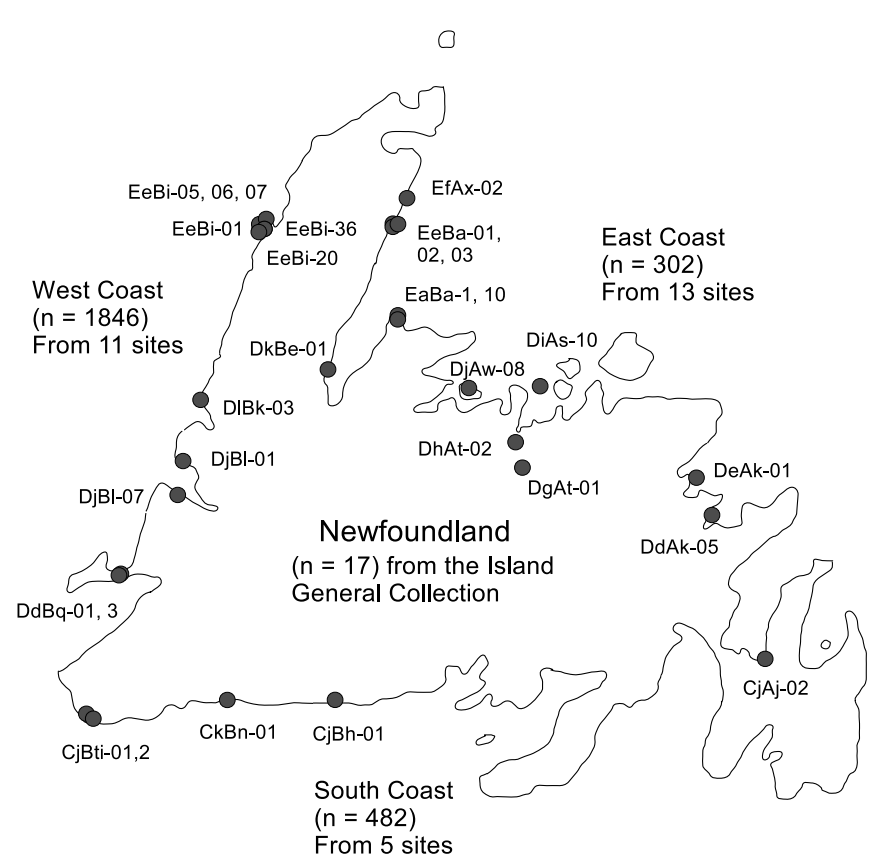

FIG. 2. Geographic distribution of soapstone vessels on the Island of Newfoundland, showing specific site locations in the West Coast, East Coast, and South Coast areas.

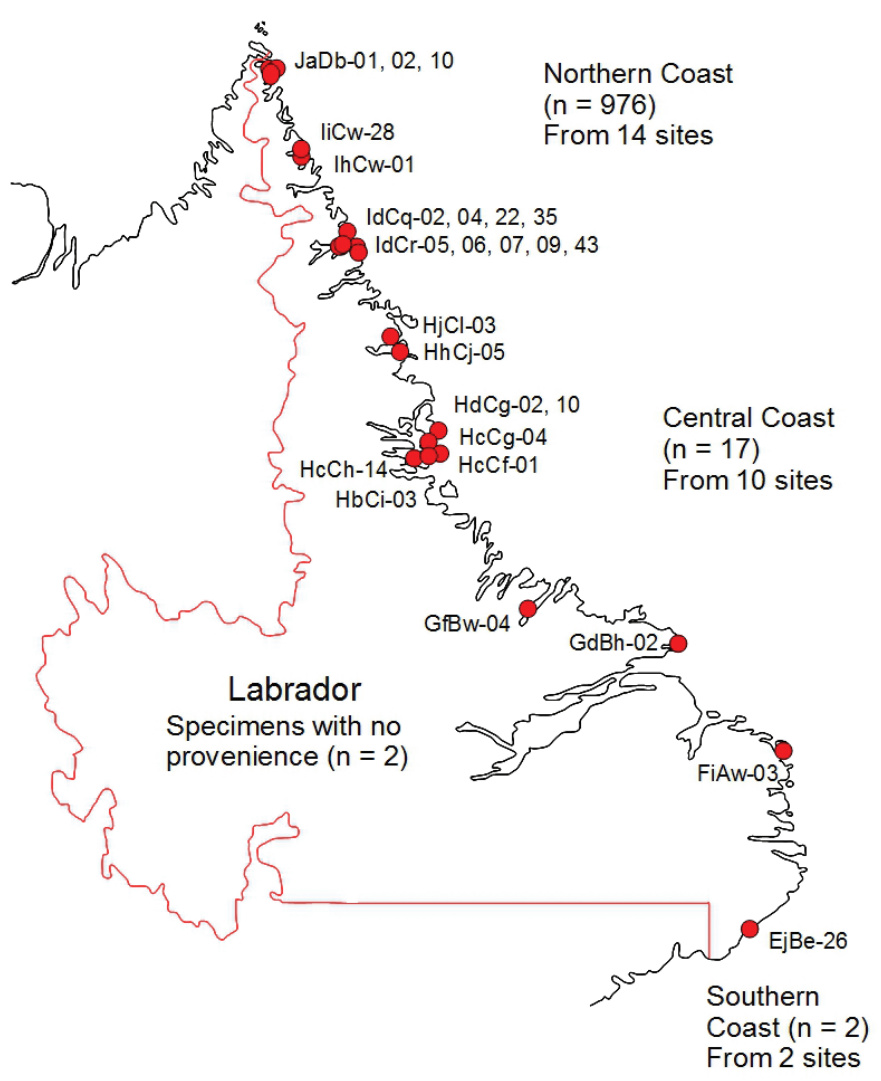

FIG. 3. Geographic distribution of soapstone vessels in Labrador, showing site locations in Northern Coast, Central Coast, and Southern Coast areas. 
and the extensive nature of the six decades of research that have been carried out there, are key factors in the amount of recovered soapstone. Thus, while it might be argued that the Phillip's Garden materials skew the study results, the vast amount of soapstone is also representative of a thousand years of repeated occupations.

Looking at the regional distribution of soapstone vessels on the Island of Newfoundland, there are a total of 359 sites (262 Dorset and 97 Groswater). Of these, the West Coast accounts for 1846 specimens from 11 sites; the South Coast for 482 specimens from five sites; and the East Coast for 302 specimens from 13 sites. In Labrador, there are a total of 519 sites (435 Dorset and 84 Groswater). Of these, Northern Labrador accounts for 976 specimens from 14 sites; Central Labrador for 17 specimens from 10 sites; and Southern Labrador for two specimens from two sites.

From these observations, it is noted that the distribution of soapstone across the province and within regions is dominated by three sites: Phillip's Garden, Cape Ray, and Shuldham Island 9. It is suggested that this distribution is due to a number of factors that relate to the history of excavation at the large productive sites. If we remove these few sites from the equation, then the distribution is relatively homogeneous, except perhaps in southern Labrador, where there are generally few Paleo-Inuit sites.

If one factors out the amount of soapstone at each site and compares only the simple presence or absence by geographic area, a surprising observation is revealed. From the 359 sites on the Island of Newfoundland, soapstone is found at approximately $8 \%$ of the sites (28 of 359). In Labrador, from the 519 sites, soapstone is found at approximately $5 \%$ of the sites (26 of 519). This result suggests that soapstone vessels are almost twice as likely to be found on Dorset and Groswater sites on the Island of Newfoundland as in Labrador. This is surprising for a couple of reasons. First, on the whole, sites tend to be more exposed in Labrador, and large artifacts such as soapstone vessels are more easily located. Second, soapstone vessels (particularly lamps) may be functionally more important in more northern areas, where there are longer periods of darkness and the production of light is essential.

The observations of this study support the hypothesis that the importance of soapstone to Paleo-Inuit peoples in Newfoundland and Labrador, relative to their more northerly counterparts, might be explained in both functional and socio-cultural terms (Erwin, 2001). For one, Dorset living in more southerly latitudes did not experience total winter darkness, nor were they in short supply of wood for fuel. It is therefore suggested that: 1) the use of soapstone vessels may have transcended simple functional requirements for the production of heat and light and for cooking; 2) soapstone appears to have had less of a functional significance to Newfoundland Dorset groups than to their Labrador and Arctic counterparts; and 3) that social and cultural meanings of soapstone, which were a product of thousands of years of Paleo-Inuit adaptation, not only endured, but were

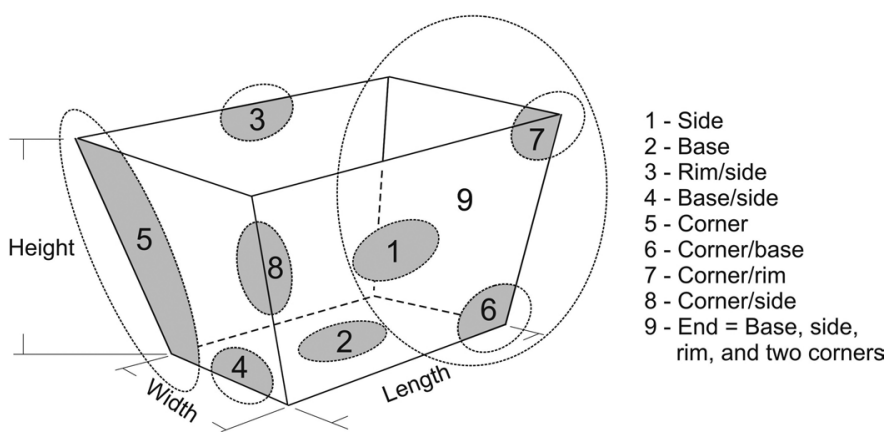

FIG. 4. Diagram of soapstone vessel attributes measured and described in this study.

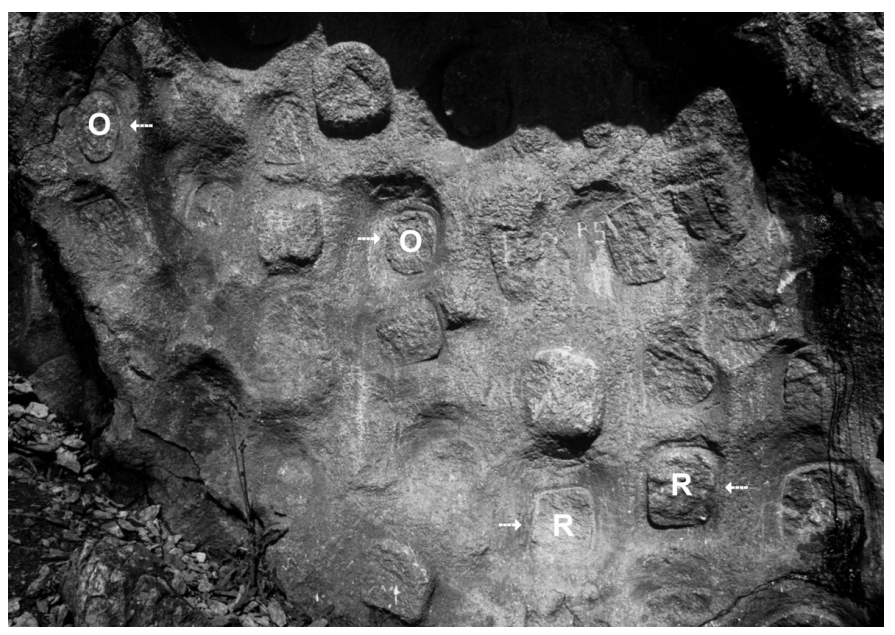

FIG. 5. View of the Fleur de Lys quarry showing soapstone vessel production scars. $\mathrm{R}=$ rectangular and $\mathrm{O}=$ ovoid. The average size of the preform scars is $20 \times 24 \mathrm{~cm}$.

perhaps stronger on the Island of Newfoundland, despite the alternatives (winter daylight and available firewood).

\section{METRIC ANALYSIS}

Notwithstanding the large size of the collection, it contained fewer than two dozen complete and mended whole vessels. To obtain a clear representation of the full range of vessel characteristics, it was necessary to examine all of the vessel fragments in order to piece together a statistically reliable analysis of vessel sizes and shapes.

The basic dimensions of every soapstone fragment were measured and recorded, noting, where possible, any physical attributes and evidence of residue that might be useful in determining vessel form and function. These included the identification and recording of vessel portion, stylistic attributes, including rim finish and decoration, and all dimensions as defined in Figure 4. The presence or absence of residue and its location on the vessel were also recorded.

As documented (Erwin 2001:72) at the Fleur de Lys soapstone quarry, vessel shapes are generally defined as either rectangular or ovoid (Fig. 5). From the sites on the Island of Newfoundland, virtually all the vessel types are 

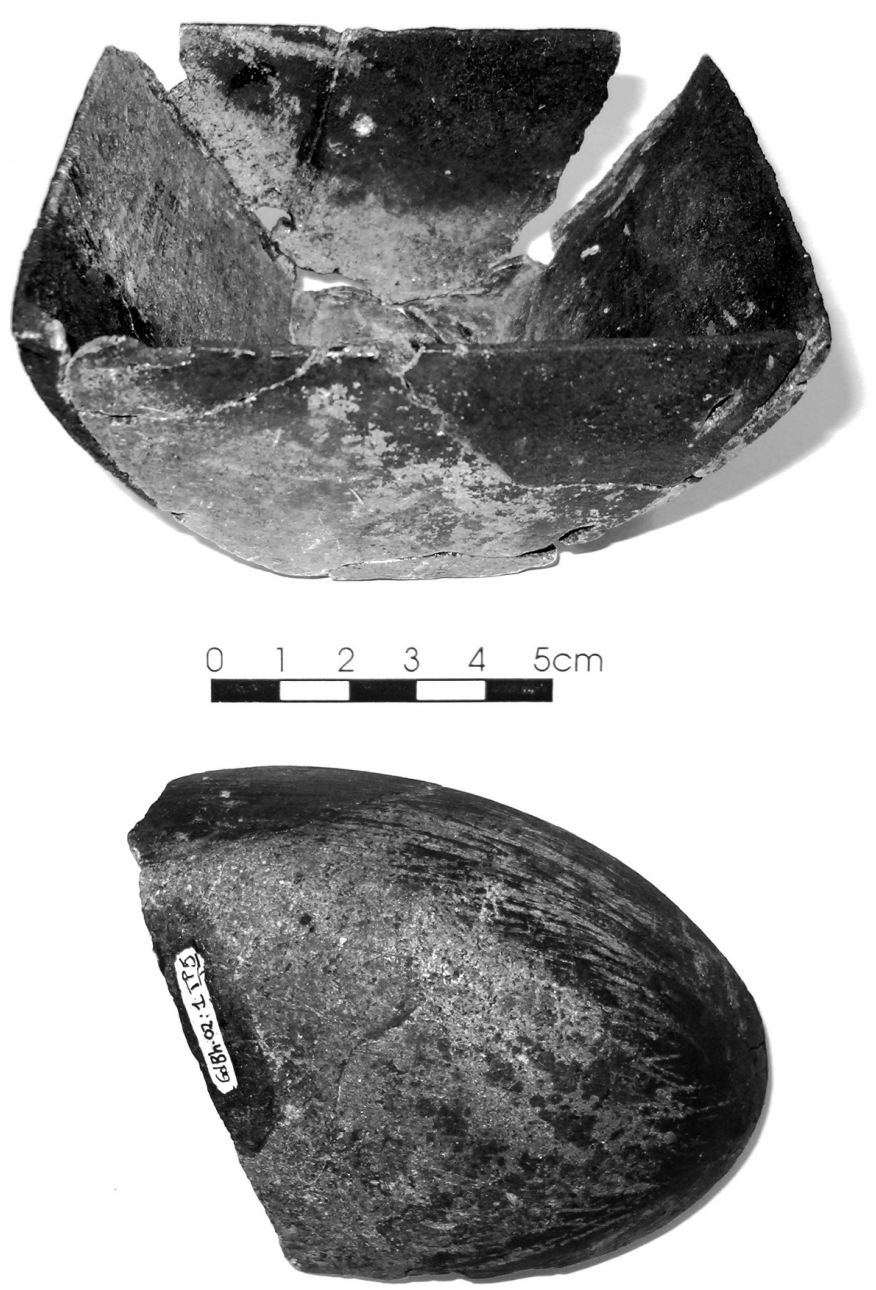

FIG. 6. Examples of rectangular and ovoid soapstone vessels.

rectangular, with the exception of 12 ovoid specimens. From Labrador, 413 were rectangular and 461 were ovoid forms (Fig. 6).

On the Island of Newfoundland, 73\% (262 sites) are Dorset and 27\% (97 sites) are Groswater. In Labrador, 84\% (435 sites) are Dorset and 16\% (84 sites) are Groswater. Given that Groswater sites generally contain very little soapstone and that they are found in similar percentages both on the Island of Newfoundland and in Labrador, they are not a factor in the preponderance of rectangular forms noted at the Fleur de Lys quarry. Rather, the higher percentage of ovoid vessel types can be attributed to the presence of Late Dorset in Labrador (who are not present on the Island of Newfoundland). As the majority of these ovoid vessels were discovered to be from Shuldham Island 9 (a Late Dorset site), this is, in fact, the case.

Rim finish is perhaps the most significant vessel attribute in this study. In general, four main styles of rim finishes were observed: Square, Convex, Straight and Biconvex (Fig. 7). Of the total 849 vessel fragments that were identified, $360(42 \%)$ are Straight Exterior, 200 (24\%) are Biconvex, 107 (13\%) are Convex Exterior, and 100 (12\%)
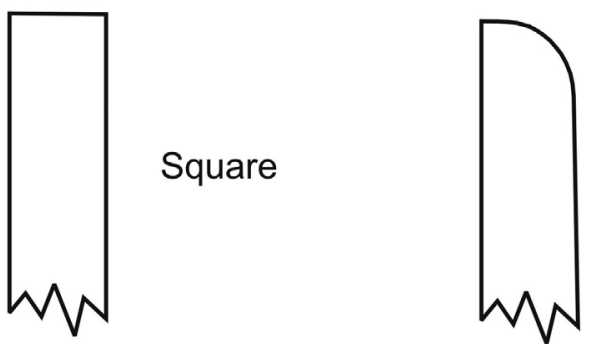

Convex

- interior

- exterior

- undetermined
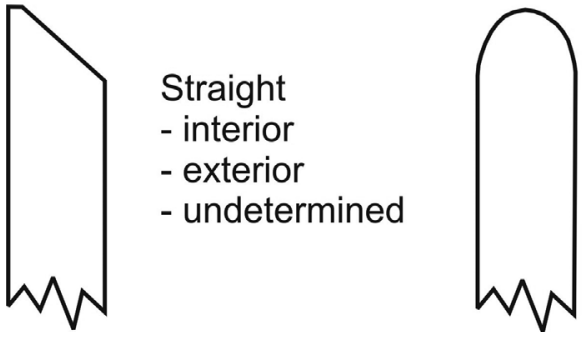

Biconvex

FIG. 7. Types of rim finishes found on soapstone vessels in Newfoundland and Labrador.

TABLE 1. Rim finishes: Newfoundland versus Labrador.

\begin{tabular}{lccc}
\hline \hline Type of rim & Newfoundland & Labrador & All province \\
\hline Biconvex & 83 & 117 & 200 \\
Convex exterior & 95 & 12 & 107 \\
Convex interior & 0 & 6 & 6 \\
Square & 33 & 43 & 76 \\
Straight exterior & 344 & 16 & 360 \\
Straight interior & 9 & 91 & 100 \\
Total identified rims & 564 & 285 & 849 \\
\hline \hline
\end{tabular}

are Straight Interior. These results are summarized and compared in Table 1. While these results may look unremarkable at first glance, it is only when you compare the differences of finish types between the Island of Newfoundland and Labrador by interior versus exterior types that an important pattern emerges. In this regard, as summarized in Table $2,78 \%$ of the finished rims from the Island of Newfoundland have exterior finishes, while only $2 \%$ have interior finishes. Conversely, only $10 \%$ of the rims from sites in Labrador have exterior finishes. From this, there is good evidence to suggest that exterior rim finishes (of any type) are a stylistic trait that can be attributed to the Island of Newfoundland, and that interior rim finish is a Labrador stylistic trait. Similarly, square or biconvex finishes are more likely to be attributed to Labrador.

From the research at the Fleur de Lys quarry, it was noted that the maximum size of preform scar was approximately $30 \mathrm{~cm}$ in length or width, and that the presence of larger finished vessels would suggest that such specimens were produced elsewhere. From the complete or partially complete specimens for which the length or width of the vessel (or both) could be measured, the following observations were made.

From the Island of Newfoundland, 11 very large vessels $(31.2-65 \mathrm{~cm}$ in size) were documented, the four largest from Phillip's Garden. Three of those four had exterior rim finishes, and the other one had a square finish. From 
TABLE 2. Newfoundland versus Labrador: interior/exterior rim finishes.

\begin{tabular}{lccrr}
\hline \hline Type of Rim & Newfoundland & \% of Rims & Labrador & \% of Rims \\
\hline Exterior & 439 & 78 & 28 & 10 \\
Interior & 9 & 2 & 97 & 34 \\
Square/biconvex & 116 & 20 & 160 & 56 \\
Total identified rims & 564 & 100 & 285 & 100 \\
\hline \hline
\end{tabular}

TABLE 3. Newfoundland versus Labrador: Interior/exterior residue patterning.

\begin{tabular}{|c|c|c|c|}
\hline Location & Interior (Lamp) & Exterior (Pot) & All vessels with visible residue on one side \\
\hline Newfoundland & $326(40 \%)$ & $476(60 \%)$ & $802(100 \%)$ \\
\hline Labrador & $241(60 \%)$ & $159(40 \%)$ & $400(100 \%)$ \\
\hline
\end{tabular}

Labrador, four very large vessels $(30-36 \mathrm{~cm}$ in size) were documented. One had an exterior rim finish (and body decoration), another had a square finish, and the remaining two were ovoid vessels with no apparent rim finish. Apart from these few exceptions, it appears that the preform sizes at Fleur de Lys are consistent with the finished vessels retrieved from sites from both Newfoundland and Labrador.

\section{RESIDUE PATTERNING}

The final attribute to be addressed is residue patterning as it pertains to vessel use. This portion of the study is based on a couple of simple premises regarding the use of the two predominant vessel types: lamps and cooking vessels. Cooking vessels are placed on or over a heat source that burns and encrusts the bottom exterior portions of these kinds of vessels. The heaviest residue tends to be on the bottom of cooking vessels, and the residues taper up along the sides. Lamps burn materials within, and therefore residues are predominantly on the interior of these vessels. Often there is almost no residue in the bottom of a lamp, with most of the residue on the interior sides of the vessel.

Of vessels recovered from the Island of Newfoundland, 712 of the specimens had residue on both sides, which suggests post-depositional burning. Interior residue was observed on 326 specimens, which is consistent with lamp use. Further it was noted that two of these specimens are ovoid, and both from Phillip's Garden. Exterior residue was noted on 476 specimens, which is consistent with cooking vessel use, and all of these are rectangular except for two ovoid specimens, both from Rattling Brook (DjAt-01).

Of vessels recovered from Labrador, it was noted that residue on both sides accounted for 397 of the specimens, which suggests post-depositional burning. Of the identifiable fragments, interior residue was noted on 241 specimens, which is consistent with lamp use. Of these, 87 were rectangular and 142 ovoid. Exterior residue was noted on 159 specimens, which is consistent with cooking pot use. Of these, 67 are rectangular and 81 ovoid.

On the surface, it would appear that lamp use is more important in Labrador than on the Island of Newfoundland. While this may well be true and may indicate increased reliance on the production of light in a more northerly geographic location, it is also a factor of the Late Dorset collection from the Shuldham Island 9 site, where there are almost twice as many vessels with interior residue $(\mathrm{n}=180)$ patterning as vessels with exterior residue $(\mathrm{n}=99)$. However, if Shuldham Island 9 is removed from the equation, what remains is a 50/50 split between lamps and pots (61 interior versus 60 exterior), suggesting the opposite of the initial conclusion, that lamps are more important on the Island of Newfoundland than in Labrador. If we eliminate the functional argument for the production of light in more northerly (dark) environments, how might this pattern be explained?

\section{SUMMARY AND CONCLUSIONS}

1) There are relatively few Paleo-Inuit sites containing soapstone vessels, and these tend to be cold weather aggregation sites.

2) Sites on the Island of Newfoundland are more likely to have soapstone than sites in Labrador, suggesting that soapstone vessel use on the Island was as much a cultural practice as a physical requirement.

3) Regional distinctions between Dorset in Labrador and the Island of Newfoundland can be seen in rim finishes, a difference which might also be used to explore marriage and residency patterns.

4) Vessel size is not always consistent with function, as there are both large and small lamps, though cooking vessels tend to be larger, which might be further evidence of regional variability.

5) With few exceptions, almost every vessel in the province could have been manufactured at the Fleur de Lys quarry, insofar as the maximum vessel size did not exceed the maximum preform scars.

6) Temporal distinctions are readily apparent in Late Dorset vessel forms.

A number of casual observations, which remain as yet untested, were made in this study: 
1) The farther vessels are from the soapstone quarry in Fleur de Lys, the more they tend to exhibit evidence of maintenance in the form of gouged repair holes.

2) Lamps are shorter than pots relative to base size.

3) The walls of Labrador cooking pots are sometimes thicker at the rim than near the base.

4) Estimates of minimum numbers of vessels can be calculated from corner fragments.

5) Base fragments are usually thicker than wall fragments in pots.

6) The occasional "handles" seen on a small number of vessels are restricted to the "ends" of vessels.

7) Red ochre on ovoid shaped lamps has some special significance.

Similarly, a number of other possible comparisons of stylistic attributes, such as rim finish versus vessel size, or vessel size versus geographic region, went unnoticed during the collection and measurement phase. In this respect, this study represents only a preliminary understanding of these data. To the future of soapstone vessel research, this study demonstrates that a great deal of information remains to be gleaned from soapstone vessels, which like the quarry in Fleur de Lys, have been underestimated and perhaps taken for granted. Beyond the scope of this study, these observations and conclusions further suggest the utility of examining soapstone fragments and the potential for these types of larger-scale analyses elsewhere.

\section{ACKNOWLEDGEMENTS}

Support for this research was made available through a postdoctoral grant provided by the Newfoundland Archaeological Heritage Outreach Program, and supervised by Dr. Priscilla Renouf, to whom this paper is dedicated. By generously providing me with access to the Port au Choix collections and to her lab space at Memorial University, Priscilla allowed me to analyze the sizeable collection of Port aux Choix materials that formed part of this research. I also would like to thank The Rooms, Provincial Museum Division, who not only loaned me the collections, but assisted me with identifying and safely packing the materials for transport to Memorial University. In particular, I would like to thank Elaine Anton for her assistance in this respect. I would also like to thank Stephen Hull from the Provincial Archaeology Office for providing me with valuable statistical and site location information and to Delphina Mercer and Elaine Anton for their careful proofing of my final manuscript. Finally, I would like to thank Dr. Patty Wells and the Memorial University archaeology students with whom I shared lab space for the many hours of discussion and insights on the Port au Choix soapstone.

\section{REFERENCES}

Cox, S.L. 1977. Prehistoric settlement and culture change at Okak, Labrador. PhD thesis, Department of Anthropology, Harvard University, Cambridge, Massachusetts.

Erwin, J.C. 1998. Preliminary field report for the 1997 Fleur de Lys Archaeology Project. Unpubl. ms. Available at the Provincial Archaeology Office, Department of Business, Tourism, Culture and Rural Development, Government of Newfoundland and Labrador, Confederation Building, PO Box 8700, St. John's, NL A1B 4J6.

- 1999. Fleur de Lys Archaeological Project: A report of the 1998 field activities. Unpubl. ms. Available at the Provincial Archaeology Office, Department of Business, Tourism, Culture and Rural Development, Government of Newfoundland and Labrador, Confederation Building, PO Box 8700, St. John's, NL A1B $4 J 6$.

. 2001. A prehistoric soapstone quarry in Fleur de Lys, Newfoundland. PhD thesis, Department of Archaeology, University of Calgary, Calgary, Alberta.

- 2003. Dorset Palaeoeskimo settlement patterns in White

Bay, Newfoundland. Northeast Anthropology 66:5-14.

_ 2005. Revisiting the Dorset soapstone quarry in Fleur de Lys, Newfoundland. In: Sutherland, P.D., ed. Contributions to the study of the Dorset Palaeo-Eskimos. Mercury Series Archaeology Paper 167. Hull, Quebec: Canadian Museum of Civilization. 121-132.

2010. Dorset Palaeoeskimo quarrying techniques and the production of little pots at Fleur de Lys, Newfoundland. In: Brewer-LaPorta, M., Burke, A., and Field, D., eds. Ancient mines and quarries: A trans-Atlantic perspective. Oxford: Oxbow Books. 56-66.

Fitzhugh, W.W. 1972. Environmental archeology and cultural systems in Hamilton Inlet, Labrador: A survey of the central Labrador coast from 3000 B.C. to the present. Smithsonian Contributions to Anthropology No. 16. Washington, D.C.: Smithsonian Institution Press. http://dx.doi.org/10.5479/si.00810223.16.1

- 1976a. Preliminary culture history of Nain, Labrador: Smithsonian fieldwork, 1975. Journal of Field Archaeology 3(2):123-142.

http://dx.doi.org/10.1179/009346976791490790

- 1976b. Paleoeskimo occupations of the Labrador Coast. In: Maxwell, M.S., ed. Eastern Arctic prehistory: Palaeoeskimo problems. Memoirs of the Society for American Archaeology No. 31. $103-118$.

1980. Preliminary report on the Torngat Archaeological Project. Arctic 33(3):585-606.

http://dx.doi.org/10.14430/arctic2585

LeBlanc, S. 2008. Middle Dorset variability and regional cultural traditions: A case study from Newfoundland and Saint-Pierre and Miquelon. PhD thesis, Department of Anthropology, University of Alberta, Edmonton, Alberta.

Lloyd, T.G.B. 1876. On the stone implements of Newfoundland. Journal of the Royal Anthropological Institute of Great Britain and Ireland 5:233-248.

http://dx.doi.org/10.2307/2841401 
Nagle, C.L. 1982. 1981 field investigations at the Fleur de Lys soapstone quarry, Baie Verte, Newfoundland. In: Thomson, J.S., and Thomson, C., eds. Archaeology in Newfoundland \& Labrador 1981. Annual Report No. 2. St John's: Newfoundland Museum, Historic Resources Division, Department of Culture, Recreation \& Youth, Government of Newfoundland \& Labrador. 102-129.

. 1984. Lithic raw materials procurement and exchange in Dorset culture along the Labrador Coast. PhD thesis, Department of Anthropology, Brandeis University, Waltham, Massachusetts.

Renouf, M.A.P., ed. 2011. The cultural landscapes of Port au Choix: Precontact hunter-gatherers of northwestern Newfoundland. New York: Springer. http://dx.doi.org/10.1007/978-1-4419-8324-4

Robbins, D.T. 1985. Stock Cove, Trinity Bay: The Dorset Eskimo occupation of Newfoundland from a southeastern perspective. MA thesis, Department of Anthropology, Memorial University of Newfoundland, St. John's.

. 1986. "Newfoundland Dorset" culture? In: PalaeoEskimo cultures in Newfoundland, Labrador and Ungava. Reports in Archaeology No. 1. St. John's: Memorial University of Newfoundland. 119-123.
Thomson, C. 1985. Dorset shamanism: Excavations in northern Labrador. Expedition: University Museum Magazine of Archaeology/Anthropology, University of Pennsylvania 27(1):37-49.

- 1989. Maritime Archaic and Middle Dorset occupations at Fleur de Lys: Preliminary results of 1986 investigations on the Baie Verte Peninsula. In: Thomson, J.S., and Thomson, C., eds. Archaeology in Newfoundland \& Labrador 1986. Annual Report No. 7. Newfoundland Museum, Historic Resources Division, Department of Municipal and Provincial Affairs, Government of Newfoundland \& Labrador. 250-259.

Tuck, J.A. 1975. Prehistory of Saglek Bay, Labrador: Archaic and Palaeo-Eskimo occupations. National Museum of Man, Mercury Series, Archaeological Survey of Canada Paper No. 32. Ottawa: National Museums of Canada.

Tuck, J.A., and Fitzhugh, W. 1986. Palaeo-Eskimo traditions of Newfoundland and Labrador: A re-appraisal. In: PalaeoEskimo cultures in Newfoundland, Labrador and Ungava. Reports in Archaeology No. 1. St. John's: Memorial University of Newfoundland. $161-167$. 